\title{
QUANTIFICANDO O ALTO RENDIMENTO: UM PROJETO DE EXTENSÃO BEM SUCEDIDO NO ÂMBITO DA UFPR
}

\author{
Julimar Luiz Pereira
}

Coordenador do Projeto de Extensão Universitária Avaliação do Atleta de Alto Rendimento, PROEC, UFPR, Curitiba/PR

soccer@ufpr.br

Acesso DOI: http://dx.doi.org/10.34059/ciejop.2019v28i1-14

A prática regular de atividade física é tida como um importante instrumento para o desenvolvimento biopsicossocial do ser humano. Quando o indivíduo opta por iniciar uma prática física orientada, rotinas de avaliação física são necessárias. A avaliação física tem por objetivo espelhar a situação atual do indivíduo, apontando e quantificando as suas reais necessidades, fornecendo parâmetros para uma prescrição adequada das atividades físicas a serem desenvolvidas e até mesmo apontando potenciais talentos desportivos. Entretanto a avaliação física pode também identificar indicadores desfavoráveis não apenas ao esforço físico, mas sim sugestivo de sub-desenvolvimento físico, como atrasos na estatura, ou nutrição inadequada, como no caso de evidências para obesidade. No campo de atuação do profissional de Educação Física, a aplicação de procedimentos avaliativos é uma das áreas mais valorizadas, pois permite o contato direto do profissional com a sociedade, permitindo diagnósticos baseados no desempenho físico e orgânico. As ações pertinentes à atuação desse profissional da área da saúde podem ser direcionadas para verificação da aptidão física e saúde ou do alto rendimento, quando nos referimos a atletas. As práticas avaliativas podem ocorrer em ambientes próprios como clubes, academias, ginásios e escolas. O objetivo principal do Projeto de Extensão "Avaliação do Atleta de Alto Rendimento" é desenvolver ações de avaliação do desempenho desportivo e consequente suporte ao treinamento de atletas profissionais e, principalmente, amadores. Atualmente o Projeto conta com dois bolsistas institucionais da UFPR/PROEC, com envolvimento também de voluntários, inclusive externos à UFPR. Diversos atletas de ponta e amadores já foram atendidos pelo Projeto, com destaque para as modalidades de futebol, beach soccer, tênis, lutas, atletismo, ciclismo, remo e fisiculturismo; após as avaliações os indivíduos são orientados da maneira mais personalizada, inclusive com encaminhamento à outras ações de extensão e pesquisa da UFPR. Alguns parceiros tem contribuído com o Projeto, dentre eles a Secretaria Estadual de Esportes e Turismo do Paraná, o São Joseense F.C., a CBF, a American Top Team (considerada a melhor equipe de MMA do mundo e sediada na Flórida/EUA) entre outros. Desta forma já observamos uma maior valorização, de maneira discreta no âmbito da UFPR, mas muito maior pela comunidade desportista do Paraná no sentido de valorizar a prática da atividade física, seu controle e orientação.

Palavras-chave: avaliação, alto rendimento, preparação física, desempenho desportivo, educação física 